\title{
Spinoza e Agamben: desobediência e potência-do-não
}

\author{
ANA CAROLINA COSTA MOREIRA *
}

RESUMO O texto tem como objetivo tensionar brevemente conceitos específicos presentes em Spinoza e Agamben apontando uma possível proximidade entre filosofia e existência no pensamento de ambos. Ao entendermos a desobediência como uma ruptura fundamental no fluxo ordinário da vida cotidiana desvela-se certo estranhamento na afluência corriqueira entre os desejos e os seus objetos e a necessidade de uma nova maneira de viver, ou novum institutum, como proposto por Spinoza no TIE. Conduzido por esse mesmo fio temático Giorgio Agamben apresenta o conceito de potência-do-não. O conceito ocupa-se da reflexão em torno de possíveis liberações de práticas que tendem a atrofiar as possibilidades de afirmação de potência do indivíduo. A potência-do-não permite o acesso a não somente ser um vivente, mas acresce força à sua condição de existência. A suspensão do sentido instituído às coisas promove, tanto para Agamben quanto para Espinosa, a desativação de valores - e poderes - vigentes. O que está por trás dos conceitos de novum institutum e potência-do-não é a possibilidade de pensar uma existência não somente mais potente, mas também capaz de serpentear tudo àquilo que constrange a potência do homem no seu modo de viver instituído.

PALAVRAS-ChaVe Maneira de viver; potência-do-não; desobediência.

* Doutoranda em História da Filosofia, PPGF - UFRJ. 
UM DOS PRINCIPAIS atributos do pensamento spinozano é a ruptura com o pensamento dualista. Essa distinção apresenta-se em diversos aspectos da sua filosofia e tem no imbricamento entre pensamento e maneira de viver uma das suas maiores expressões. A epistemologia spinozana não se sustenta sem o seu princípio ético. É o que nos diz não somente o Tractatus de Intellectus Emendatione (1661) escrito em que apresenta a sua teoria do conhecimento - mas toda extensão de sua obra.

Apesar de, para alguns comentadores ${ }^{1}$ o prólogo do TIE $^{2}$ ter valor de confissão pessoal e carregar mais caráter narrativo que filosófico, marcado talvez uma por influência cartesiana em torno do entendimento da razão humana, a passagem nos sugere haver um pressuposto basilar: o pensamento spinozano não propõe apenas uma teoria do conhecimento ou um sistema filosófico, mas exige certa tensão ética no íntimo do indivíduo. Spinoza sugere a necessidade do rompimento com o fluxo comum da vida como condiç̧ão da reforma do intelecto. A necessidade é justificada a partir da constatação de que o fluxo ordinário do cotidiano reduz a capacidade de pensar - onde pensar bem implica existir igualmente bem. Há uma fórmula paradoxal no fluxo corriqueiro da vida: ao operá-lo, o indivíduo torna-se passivo.

1 Lívio Teixeira na introdução à edição do Tratado da Reforma da Inteligência (Martins Fontes, 2004) predica o prólogo da obra como uma introdução "dramática” e sugere que o texto se refere à uma experiência pessoal, excluindo o percurso proposto por Spinoza dos pressupostos para a teoria do conhecimento do filósofo. O imbricamento entre pensamento e experiência, mais tarde amadurecido pela obra principal - Ética demonstrada segundo a ordem geométrica - nos permite reforçar a relevância de conceitos como distração, novum institutum e decisão como premissas para a teoria epistêmica e ética, marcando a nossa discordância diante a leitura proposta pelo comentador. Não há uma fissura entre o prólogo e a teoria epistêmica do TIE, ainda que a leitura proposta faça parecer.

2 O prólogo da obra spinozana é composto por dezenove parágrafos e amplamente comentado ao longo da história da filosofia. Diz no parágrafo 3: "Dava, pois, tratos ao pensamento, a ver se era possível chegar a esse novo modo de proceder ou, ao menos, a uma certeza a respeito dele, sem mudar, embora, a ordem e a conduta ordinária de minha vida. Tentei isso muitas vezes, sem resultado. As coisas que mais frequentemente ocorrem na vida, estimadas como supremo bem pelos homens, a julgar pelo que eles praticam, reduzem-se, efetivamente, a estas três, a saber, a riqueza, as honras e o prazer dos sentidos (...). Compreendemos as passagens de introdução ao seu sistema epistêmico como indissociáveis do seu traço ético, ou seja, da possíveis maneiras de viver. 
Propor uma nova maneira de pensar é um passo que exige envolvimento do ponto de vista subjetivo já que pensar e viver estão em uma dissociável relação. Assumir uma nova maneira de viver exige um desprendimento corajoso quando o que está posto não perpassa apenas aquilo que se pensa, mas atinge também o que se sente. Nesse sentido, propor-se à uma nova maneira de viver exige uma disposição sincera a um esforço sobre si mesmo - por gerar uma consequente desorganização ${ }^{3}$ interna e ressignificação do mundo.

Esse deslocamento do cotidiano, tem implicações também sociais e Spinoza mantém todas as dificuldades em evidência. Dado que em meio à ordem social estamos subjugados à certa normatividade em torno dos desejos, dos comportamentos, da maneira de pensar, romper com certo fluxo da normatividade implica em um custo:

A satisfação consigo mesmo é, na realidade, a maior coisa que podemos esperar. (...) E essa satisfação é cada vez mais, reforçada e consolidada pelas exultações (...) e, de maneira inversa, cada vez mais perturbada pela afronta. É por isso que somos guiados, sobretudo, pela glória e podemos ainda que com dificuldades, suportar uma vida de opróbrio. ${ }^{4}$

É marcada de maneira literal em diversas passagens da obra spinozana que a reforma do entendimento - ou seja, a predisposição à ética - ainda que implique no aumento de potência e em estados possíveis de alegria, carrega consigo um ônus. Inclinar-se à essa nova disposição sequer tem início se não houver uma relação sincera no íntimo de si mesmo. Somente a aparente adesão aos pressupostos spinozanos não é suficiente para que a correção do intelecto e o percurso à beatitude se dê. É necessária a

3 Nesse sentido, a imagem trazida por Lispector na obra A paixão segundo G.H (1963), ilustra a desestabilização subjetiva daquele que, corajosamente, se propõe à uma nova significação do mundo. Compreendemos haver entre as obras uma proximidade possível se partirmos do pressuposto que ambas tratam de um processo de reforma ética e reconfiguração do olhar diante do que está dado na vida ordinária. Para Spinoza, assim como para Lispector, o desnudamento das formas instituídas exige um sincero esforço sobre si e uma nova maneira de viver. A essa empreitada, há uma consequente 'desorganização' interna:

"Não sei o que fazer do que vivi, tenho medo dessa desorganização profunda. Não confio no que me aconteceu. Aconteceu-me alguma coisa que eu, pelo fato de não saber como viver, vivi uma outra? A isso quereria chamar desorganização, e teria segurança de me aventurar, porque saberia depois para onde voltar: para a organização anterior. A isso prefiro chamar desorganização pois não quero me confirmar no que vivi - na confirmação de mim eu perderia o mundo como eu o tinha, e sei que não tenho capacidade para outro." (LISPECTOR, 2009, p.09)" 
abdicação interior do desejo de obedecer ao que reduz a capacidade de pensar/viver - que de certa forma é o que sustenta a normatividade.

Note-se que, apesar de haver um traço soteriológico, a sugestão à um novo modo de significação do mundo e das relações que o compõem passa à largo de uma tendência ideológica ou fixidez em determinada doutrina de qualquer caráter. O salto no propósito salvacionista em Spinoza está em não haver nenhuma possibilidade de aderência às forças externas que guiem ou conduza os afetos do indivíduo - tanto quanto possível. É exatamente o oposto de qualquer possibilidade de sugestão à escopos ideológicos de qualquer natureza. A ética, a salvação, o aumento de potência está sempre em relação com causas determinadas pelo próprio indivíduo.

Ao associar, no TIE, o fluxo da vida ordinária - que fragmenta a capacidade da existência - a um modo de vida que está posto como o corrente, Spinoza denuncia que os desejos por quais inclina-se, muitas vezes não são causados por si mesmo. Os pensamentos, os interesses e as volições são assim conduzidas por outras razões que não o próprio indivíduo, tornando-o servo das causas desconhecidas que o conduz. É sob esse contexto que se dá a desobediência como fundante para a liberdade.

Nos é particularmente cara a importância da desobediência, se entendermos por esse conceito uma não-adesão ao fluxo corriqueiro do que está posto, e que constrange o aumento da potência do indivíduo. Essa não-aderência tem um valor fundante em todo pensamento ético spinozano visto não haver nenhuma outra importância na filosofia senão a utilidade - afim de uma existência mais potente.

Compreendemos que a desobediência, carrega a recusa não somente mediante a constrangimentos externos - sejam manifestos por regras, ordens ou imperativos de qualquer ordem - mas há nesse conceito também a possibilidade de se referir ao que toca o âmbito íntimo. Desobedecer não significa necessariamente estabelecer um confronto, mas em seu sentido mais significativo, implica em uma não-adesão principalmente de natureza subjetiva àquilo que reduz a capacidade de existir.

Para Spinoza, a obediência é um valor associado ao consenso estabelecido em meio à organização civil:

Não se pode (...) conceber-se o pecado, mas pode-se, certamente concebê-lo no estado civil, no qual o que é bom e o que é mau é decidido por consenso, e 
cada um está obrigado a obedecer à sociedade civil. O pecado não é, pois, senão uma desobediência (inobedientia), que é punida apenas por causa do direito da sociedade civil. E, inversamente, a obediência é creditada ao cidadão como mérito, pois, por causa dela, ele é julgado digno de desfrutar dos benefícios da sociedade civil. 5

Nesse sentido, a desobediência se refere a determinada norma estabelecida extrinsecamente, não sendo um atributo que explique a sua própria natureza. Ser desobediente implica, necessariamente, haver sempre uma causa exterior a qual não se adere, ou seja, se é desobediente em relação a algo e não em uma natureza per se.

A tarefa da teoria dos afetos em tornar lúcidas as motivações pelas quais deseja-se àquilo que se quer, se torna fundamental nesse processo à liberação da obediência. A desobediência que tratamos não tem senão um desafio a superar - reconhecer a 'extimidade' dos próprios afetos. É necessário tratar dessa suposta intimidade como problemática, quando, as motivações de causas desconhecidas tornam-se trilha de obediência.

Para Frédéric Gros (2018), um dos desafios da relação entre servidão e liberdade está em haver uma inércia passiva diante dos hábitos de obediência. E a normatividade é reforçada através do hábito junto à tendência ao 'seguidismo' - onde os homens alinham o seu comportamento tendo como referência não a sua própria potência, mas o hábito de todos os outros. Podemos entender essa tendência ao normativismo como um hábito à perda de si. Sem dúvidas que o normativismo produz alegrias passivas, quando há aderência subjetiva do individuo e do ponto de vista social, a sua adesão traz garantias confortáveis tanto do ponto de vista moral quanto ao que toca o direito civil.

O rompimento com a servidão exige um olhar sobre as manifestações silenciosas de aderência ao que está posto e implica em uma dupla relação consigo mesmo: observar-se com lucidez é um exercício ético e cognitivo. Do ponto de vista ético exige sinceridade diante dos afetos que se manifestam e sob o aspecto epistêmico, é a contemplação de $\mathrm{si}^{6}$ que garante os gêneros mais adequados de conhecimento.

5 SPINOZA, EIVP37S2

6 Para Spinoza no TIE, conhecer implica em uma das quatro formas possíveis: $i$ ) o ouvir dizer; ii) a experiência vaga; iii) o conhecimento inadequado da essência e; $i v$ ) o conhecimento da essência. A diferença das duas primeiras formas para as duas últimas envolve a capacidade reflexiva do olhar sobre si - ainda que em estatutos distintos. Enquanto a terceira forma permite o conhecimento da essência - ainda que não adequadamente - conhecemos (intelligimus) o efeito porque o sentimos e 
A descontinuidade do movimento de distração que reduz potência - ou o que nomeamos como hábito da perda de si - implica pensarmos não somente naquilo que se pode, mas também sobre aquilo que se pode não fazer. Decerto que a potência carrega natureza de afirmação de si, mas, em relação a causas exteriores que constrangem o seu aumento, a potência-do-não é, ainda que paradoxalmente, uma afirmação de si.

Spinoza define no livro V o que entende por impotência:

Percebe-se facilmente, enfim, pelo que foi anteriormente dito, a diferença entre a verdadeira virtude e a impotência: a verdadeira virtude nada mais é do que viver exclusivamente sob a condução da razão, enquanto a impotência consiste em o homem se deixar conduzir apenas pelas coisas que estão fora dele e em ser determinado por elas a fazer aquilo que o arranjo ordinário das coisas exige e não aquilo que exige a sua própria natureza, considerada em si mesma. ${ }^{7}$

O que a proposta spinozana nos permite afirmar é a importância do esforço sobre si como caminho possível de aderência a uma ética que abre a possibilidade para uma nova e potente leitura diante do mundo. Por mais que a ontologia de Spinoza ofereça um pensamento por muitas vezes difícil de ser experimentado devido à radical ruptura com fundamentos que são longamente sustentados pela tradição - o dualismo clássico, por exemplo - embora proponha um homem em condições de "porosidade", estabelecendo uma necessária troca permanente entre as causas internas e externas, pensar a desobediência reforça o caráter ético do ponto de vista interno e subjetivo do homem.

Ao tempo que essa posição soa como atomista e antes mesmo de parecer haver um apoio à ideia de um individuo encerrado em si, um dos maiores atributos da ética spinozana é o seu imbricamento com a política. Ou seja, o homem, em Spinoza mais que

concluímos a causa sem a conhecer. Conhecer o efeito nesta modalidade, consiste em conhecer a própria sensação (MARTINS, 2017). Mesmo havendo a necessidade de manter cuidado, já que as sensações podem ser confundidas pela imaginação, ou seja, ainda que correndo o risco de um conhecimento difuso e incerto, o que cabe destaque é a distinção metodológica necessária entre os modos. Dos dois primeiros ao terceiro e quarto modos de conhecimento, o que muda metodologicamente é a presença da reflexão sobre si - para nós não está em jogo a adequação das ideias. O livro II da Ética apresenta uma epistemologia distinta, mas sustenta a importância da contemplação de si como método de conhecimento. Contemplar a afecção do corpo é a percepção da mente diante da afecção que ocorre no corpo. Contemplar a si, é, assim, uma maneira de pensar, ainda que a mente contemple simultaneamente a ideia do corpo e os corpos externos que causam a afecção.

7 SPINOZA, EIVP37S1 
um simples animal social ou, por sobrevivência, coletivo, o homem, em sua natureza potente é parte de uma relação com os outros e o esforço de aprimoramento sobre si, implica em um necessário esforço de aprimoramento sobre os outros homens.

Assim, a política em Spinoza pode ser o resultado de um esforço ético. Se considerarmos como pressuposto a importância da busca por si mesmo - e aqui tratamos de uma reflexão do ponto de vista afetivo e epistêmico - a política/ética em Spinoza tem como um dos seus espaços o si mesmo do indivíduo. E cabe sublinhar o si mesmo não implica em um eu encerrado em si.

Tratar da desobediência do ponto de vista ético, sugere haver, ainda que sempre provisoriamente, uma insistência na própria natureza diante de forças exteriores, ainda que esse processo possa ocorrer em um cenário de amplo matiz de intensidade. $\mathrm{O}$ olhar sobre os afetos que se manifestam intimamente e a constatação de uma aderência a causas exteriores que reduzem potência abre-nos a possibilidade de pensar a não-aderência, o cessar o movimento, o não-fazer como uma maneira de agir, se a entendermos como uma posição que aumenta a potência de existir.

Assim, não é somente à medida que se pode fazer, mas também a capacidade de interromper o fluxo daquilo que enfraquece a potência que permite o aumento da capacidade de existir. O não-fazer, paradoxalmente, assume assim, estatuto de ação. Torna-se uma modalidade particular do agir.

\section{O NÃO-FAZER COMO MODO DE AGIR}

Ao concordarmos com a desobediência como pressuposto ético, torna-se possível estabelecer uma relação entre o novum institutum e a potência-do-não, proposto por Giorgio Agamben. O conceito de potência-do-não ou potência do não fazer, é proposto pelo filósofo italiano a partir da leitura de escritos aristotélicos, onde o filósofo antigo afirma, no livro IX da Metafísica, ser a impotência (adynamia) uma privação contrária à potência ${ }^{8}$ (dynamis). Para Aristóteles toda potência é impotência do mesmo em e ao mesmo tempo de que é potência. Para Agamben, poder não exercer a sua

8 A potência referida por Aristóteles no livro IX da Metafísica e no livro II do De anima não é a potência genérica segundo a qual dizemos que uma criança pode tornar-se arquiteto, mas a que compete a quem já domina o saber correspondente. Aristóteles chama essa potência de habilidade ou capacidade (hexis). (AGAMBEN, 2018). 
própria potência é sempre potência. Ou seja, o homem é o vivente que, existindo sob forma de potência, pode tanto fazer como não fazer àquilo que pode. O homem pode dominar as suas capacidades a ponto de poder a não-operação da sua capacidade:

Nada nos torna tão pobres e tão pouco livres como esse estranhamento da impotência. Aquele que é separado do que pode fazer pode, porém, resistir ainda, pode não fazer. Aquele que é separado da sua impotência perde, ao contrário, principalmente, a capacidade de resistir. E como é somente a ardente consciência do que não podemos ser que garante a verdade do que somos, assim é apenas a visão lúcida do que não podemos ou podemos não fazer que dá consistência ao nosso agir. ${ }^{9}$

Não é a passagem da potência ao ato, senão a própria potência-do-não o que convocamos como ponto de proximidade entre os pensadores, visto em Spinoza e em Agamben - este apoiado no pensamento aristotélico - a ideia de contingência tecerem tramas conceituais de premissas senão anatagônicas, ao menos muito distintas. Outro ponto de diálogo entre os dois pensadores, se estabelece na utilidade da filosofia através do reconhecimento da potência do pensamento. Diante da possibilidade da potência, Agamben afirma ser a filosofia, na sua intenção mais profunda, uma firme reinvindicação da potência. Nos diz: "não o pensamento, mas a potência de pensar; não a escritura, mas a cândida folha é o que a filosofia não quer de nenhuma maneira esquecer.”o

A potência-do-não funciona como uma espécie de suspensão da relação com um desejo estruturado em uma subjetividade de convenção moral, apontando-se um então novo modo possível de viver. Interromper a lógica de aderência ao desejo que constrange o indivíduo é uma maneira de insurgir a potencialidade de uma vida mais potente, que pode vir a ser expressa.

Em Spinoza, a vivência do indivíduo implica em uma dimensão psicofísica. Tudo opera a partir dessa estrutura. A desorganização causada pela potência-do-não diante de uma vida convencionalmente menos potente do que pode - se torna entrada a uma nova expressão da potência em diversas esferas e não somente no âmbito cognitivo.

9 AGAMBEN, Nudez, p.73

10 O autor apresenta em Bartebly, ou da Contingência uma imagem sustentada por filósofos antigos e mais tarde, por teólogos onde a potência do pensamento assume lugar de rasura tabulae, ou tábula rasa, folha em branco. (AGAMBEN, p.20) 
O que entra em jogo é a abertura para um novo modo de viver - onde há um necessário imbricamento entre as esferas afetivas e epistêmicas. Negar o que está posto, possibilita sem dúvidas, um estado de desorganização - já que todo objeto de desejo e maneira de entendimento do indivíduo apoia-se nessa estrutura - e cai-se em um estado de confusão que pode soar como total vazio ou, como na obra de Spinoza, se encara o caos potente de novas configurações.

Para Peter Pal Pelbart, a leitura de Agamben sinaliza que um mundo desprovido da potência-do-não, onde tudo resumir-se-ia em necessidade e impossibilidade, é um mundo sem sujeito. Para Agamben e para Spinoza, a vida em seu sentido potente não se resume em uma condição puramente fisiológica. Em seu estado de espontaneidade, a vida é afirmação de potência. Abrem-se possibilidades de existência em matizes distintas - já que a vida é expressa nas singularidades dos modos finitos.

Suspender a ordem estabelecida como modo de leitura do mundo em uma subjetividade constrangida é anunciar a insurgência da potência. Mas esse não é um comando com embasamento no estatuto da moral. Ou seja, não se caracteriza a potência-do-não como uma reação, uma defesa, mas como uma atividade, como expressão do vigor da potência. Apesar de disposta em um aparente binarismo, a potência-do-não, ocupa um certo entre. Não se trata de uma reação, de um não-poder-fazer, nem de um fazer, trata-se da indiscernibilidade: não é sim nem não, é uma afirmação da suspensão da possibilidade. Na figura de Bartebly, Agamben personifica essa fissura, que encontramos também em Spinoza, a partir da suspensão do desejo que move a vida comum no prólogo do TIE. Há um estar em suspenso quando a engrenagem da vida é silenciada, visto que a vida em seu sentido forte não é uma transmutação para uma outra via imediatamente conhecida, mas para a possibilidade de outras formas de viver. Nos ilustra Agamben:

(...) no estar suspenso [havia] não uma simples indiferença, mas a experiência de uma possibilidade ou de uma potência. O que se mostra no limiar entre ser e não ser, entre sensível e inteligível, entre palavra e coisa , não é o abismo incolor do nada, mas a espiral luminosa do possível." ${ }^{11}$

11 AGAMBEN, Bartebly, ou da Contingência, p 32. 
A suspensão do modo de viver e de desejar estabelecidos exige, certo aumento na atenção sobre si e sobre o que se deseja - e uma intensidade na presença de si mesmo em uma medida maior que o exigido pelo cultivo dos hábitos corriqueiros. Não se pode perder de vista que a potência do não-fazer implica na lucidez do não-agir como ação - no seu mais forte sentido. Essa não-agência que é uma atividade, quando disposta no âmbito afetivo, dos desejos correntes, rompe com o fluxo de normatividade na sua esfera mais profunda. Se é desobediente em relação ao modo de vida que fragmenta a capacidade de agir não como uma oposição gratuita, mas em suas distintas nuances. Essas desativações serão tão diversas quanto os modos, pois o que está em jogo é o modo de vida em relação às singularidades. Não se trata de um novo estatuto moral, mas de uma predisposição ética. O aumento ou redução de potência se refere sempre à singularidade, não mais a causas exteriores ou a uma conduta de ordem moral pré-estabelecida.

Esse rompimento afetivo, subjetivo, essa potência-do-não resulta não na simples ruptura com os desejos, com os modos de viver e com tudo que compõe a vida, mas sugere um pequeno deslocamento - uma nova relação afetiva, onde ainda que não se atribua imediatamente um novo valor a tudo que já se conhecia, ao menos suspende o seu significado corrente. Essa nova relação no plano dos afetos, na intimidade do indivíduo é que permite a real desativação dos poderes exteriores. Somente com o não-operar das forças exteriores que reduzem a capacidade de existir, abre-se a possibilidade para outras maneiras de viver no mundo.

Essa suspensão de valores nos permite atribuir uma relação direta e não mais mediada entre a singularidade e as coisas, atribuindo novas formas de uso e significados. Impotência e potência-do-não devem ser compreendidas como coisas distintas. É preciso apontar que em meio à potência-do-não, abrem-se numerosas possibilidades de novos usos da potência. É o desligar da forma corriqueira de vida e a possibilidade de múltiplas outras maneiras.

Dado que a cessão do movimento corriqueiro que gera o hábito da perda de si - que mantém a potência de agir em condições mornas - abre-nos o intimo de si mesmo como um espaço fundante para edificação do exercício da ética, podemos pensar que esse deslocamento em meio ao ordinário permite-nos inferir o cotidiano como o tempo para exercício dessa desobediência. 


\section{O COTIDIANO COMO TEMPO DA DESOBEDIÊNCIA}

O exercício em busca de uma nova maneira de pensar tem uma grande exigência em relação à presença do indivíduo. Essa inteireza é invocada tanto na relação consigo mesmo quanto com os corpos externos que não cessam as suas afecções. Essa exigência de presença, isso que chamamos de 'presentificação', garante não somente o enlace consigo mesmo - em atenção aos encontros que aumentam a própria potência - mas implica também em um exercício de ressignificação do valor do cotidiano como o tempo que institui as condições de existência. É nesse sentido que a filosofia de Spinoza marca, como sugerido por Martins (2018) uma distinção entre o real e a atualidade.

A disposição a uma nova maneira de viver que tem início com o cessar do 'seguidismo' em direção a causas externas à própria natureza reconfigura o mundo, atribuindo-lhe novos significados. A existência ganha uma outra dimensão: é no cotidiano que se abrem as possibilidades de uma potência mais forte. Estão estabelecidas as vias de imbricamento entre a filosofia e a vida e é onde torna-se tautológico o ordinário: é contra ele e através dele que se dá o estabelecimento de uma nova relação com o mundo. É preciso que haja um pequeno deslocamento no corriqueiro, admitindo-se, como proposto por Pierre Hadot, certa ambiguidade na ideia de cotidiano - é preciso aceitar o comum, mas também dele se desenraizar. Um desenraizamento à medida que o cotidiano consiste em juízos ou comportamentos dominados pelos hábitos e preconceitos. ${ }^{12}$ A filosofia permite uma espécie de desenraizamento, ao tempo que é inseparável do cotidiano. Para o estudioso francês:

A filosofia não é uma atividade reservada a um contemplativo que fica em seu gabinete de trabalho e que cessaria a partir do instante em que o deixa ou em que deixa a sala de aula, mas trata-se antes de uma atividade que é absolutamente cotidiana ${ }^{13}$.

Entender o cotidiano como o tempo e a si mesmo como espaço de presença para o aumento da capacidade de existir conduz a filosofia de Spinoza a uma série de possibilidades de vias de pensamento. A compreensão da ética como uma busca pelo aprimoramento humano tendo como consequência o reflexo na maneira de viver e, o

12 HADOT, 2014, p.347.

13 HADOT, Exercícios Espirituais e filosofia antiga, 2014, p 348. 
que é o mesmo, na relação com os corpos que compõem o nosso entorno, permite-nos pensar que a política ganha uma nova possibilidade. O poder do não-fazer, o aumento da presença de si e a atribuição de novos sentidos ao cotidiano compõem o pano de fundo da ética e consequentemente da política em Spinoza. Ou seja, uma melhor compreensão de si implica, para Spinoza, em um viver ético, visto que o homem que se mantém de acordo com ideias adequadas necessariamente quer o bem para si e para todos os demais. Diz:

(...) a razão não exige nada que seja contra a natureza, ela exige que cada qual ame a si próprio (...) que deseje tudo aquilo que efetivamente, conduza o homem a uma maior perfeição(...)” E completa: “(...) os homens que buscam, sob a condução da razão, o que lhes é útil, nada apetecem para si que não desejem também para os outros e são, por isso, justos, confiáveis e leais. ${ }^{14}$

Compreender a própria natureza de modo adequado resulta em necessariamente uma política com pressupostos éticos. E nesse esforço sobre si, pressuposto para a ética do cotidiano, ou seja, a desobediência diante de uma maneira de se relacionar com os poderes vigentes também implica em pensarmos em que medida os nossos afetos reproduzem a lógica instucionalizada, na relação com o outro, reforçando condições de enfraquecimento de potência daqueles que estão em relação conosco. É ao admitir a maneira que me relaciono com o desejo como causa externa que se abre a possibilidade de inoperar esse afeto. A destituição dos poderes sob a perspectiva cotidiana ética, converge então com o campo político. Atuar a partir da busca de compreensão da natureza humana implica em um esforço sobre si e em relação com o mundo.

Eis, pois, o fim a que tendo: adquirir essa natureza e esforçar-me para que, comigo, muitos outros a adquiram; i.e, faz parte da minha felicidade o esforçar-me para que muitos outros pensem como eu e o seu intelecto e o seu desejo coincidam com o meu intelecto e o meu desejo $(. . .)^{15}$

Torna-se o cotidiano e o mais usual dele o espaço de atuação dessa nova maneira de viver. Distante de momentos apoteóticos ou de uma graça divina concedida somente aos escolhidos, o pensamento de Spinoza traz ao seio do comum a grande chance de mudança de decursos. O comum alcança o estado precioso do único lugar para uma

14 SPINOZA, Ética, EVP18S

15 SPINOZA, TIE, parágrafo 14. 
ressignificação dos poderes que reduzem potência, ou seja, é o cotidiano o espaço da filosofia pressuposta em certa desobediência. A essa altura a filosofia e a vida alcançam um estado de inseparabilidade, já que as relações se dão a partir desse esforço de compreensão das coisas, não mais mediado pela moral, mas em relação entre a singularidade e as coisas mesmas.

Compreendemos assim, a desobediência, como passo irrevogável ao caminho desse novo decurso que, ainda que apoiado em uma mesma razão humana, só pode ser experimentada de modo sincero, singular e diverso. É o homem enquanto distraído, em condição de passividade diante das formas instituídas de viver, o maior obstáculo a ser superado por essa potencialidade de existência. Dado o si mesmo como espaço e o cotidiano como o tempo para edificação da ética apoiada na busca pelo aprimoramento humano, Spinoza nos permite a concepção de possibilidades de maneiras de viver e espaços políticos sob uma nova perspectiva. E nos parece ser o desenlace com os poderes que nos constrangem o pressuposto ético vital nesta direção.

\section{REFERÊNCIA BIBLIOGRÁFICA}

AGAmBEN, G. Nudez Trad. Davi Pessoa Carneiro. $1^{\text {a }}$ edição. Belo Horizonte: Editora Autêntica, 2015 .

AGAMBEN,G. Bartebly, ou da contingência. Trad. Vinícius Honeskoo e Tomaz Tadeu. Belo Horizonte: Autêntica Editora, 2015 .

ARISTÓTELES. Metafísica. Trad. Rusconi Libri. São Paulo: Edições Loyola, 2002.

ESPINOSA, B. Ética Trad. e notas Tomaz Tadeu. $3^{\text {a }}$ edição, 1 reimp. Belo Horizonte: Autêntica Editora, 2013.

ESPINOSA, B. Tratado da Reforma da Inteligência. Trad. introdução e notas Livio Teixeira. São Paulo: Martins Fontes, 2004.

ESPINOSA. Tratado da Reforma do Entendimento. Trad. Ciro Mioranza. Edição Bilingue. Editora Scala. São Paulo, 2007.

GROS, F. Desobedecer. Trad. Célia Euvaldo. São Paulo: Ubu Editora, 2018. 
HADOT, P. Exercícios espirituais e filosofia antiga. Trad. Flavio Loque e Loraine Oliveira. $1^{\mathrm{a}}$ edição. São Paulo: É Realizações, 2014.

MARTINS, A. A primeira ideia verdadeira no TIE: ideia do corpo e ideia-da-ideia. Revista Trágica: estudos de filosofia da imanência. Rio de Janeiro, v.10 no 3, p. 58-71, 2017

MARTINS, A. SANTIAGO, H. OLIVA, L.C. As ilusões do eu: Spinoza e Nietzsche. Trad. Daniel Santos da Silva. Rio de Janeiro: Civilização Brasileira, 2011.

PELBART, P. A potência-do-não: Linguagem e política em Agamben. Revista Estudos da Lingua(gem) V. 15, N. 2 (2017): UESB, Bahia, 2017.

RIBEIRO, M. LUISA. A dinâmica da razão na filosofia de Espinosa. Lisboa: Fundação Calouste Gulbekian, 1997. 